Pacific Journal of Mathematics

RADON-NIKODÝM THEOREMS FOR THE BOCHNER AND 


\title{
RADON-NIKODÝM THEOREMS FOR THE BOCHNER AND PETTIS INTEGRALS
}

\author{
S. Moedomo AND J. J. UhL, JR.
}

The first Radon-Nikodým theorem for the Bochner integral was proven by Dunford and Pettis in 1940. In 1943, Phillips proved an extension of the Dunford and Pettis result. Then in 1968-69, three results appeared. One of these, due to Metivier, bears a direct resemblence to the earlier Phillips theorem. The remaining two were proven by Rieffel and seem to stand independent of the others. This paper is an attempt to put these apparently diverse theorems in some perspective by showing their connections, by simplifying some proofs and by providing some modest extensions of these results. In particular, it will be shown that the Dunford and Pettis theorem together with Rieffel's theorem directly imply Phillips' result. Also, it will be shown that, with almost no sacrifice of economy of effort, the theorems here can be stated in the setting of the Pettis integral.

For ease of reference the theorems mentioned above are listed below in a form convenient for our purposes. Throughout this paper $(\Omega, \Sigma, \mu)$ is a finite measure space and $X$ is a Banach space.

I. (Dunford-Pettis) [2, VI. 8. 10] Let $t: L^{1}(\Omega, \Sigma, \mu) \rightarrow X$ be a weakly compact operator whose range is separable. The there exists an essentially bounded strongly measurable $g: \Omega \rightarrow X$ such that

$$
t(f)=\text { Bochner }-\int_{\Omega} f g d \mu f \in L^{1}(\Omega, \Sigma, \mu)
$$

II. (Phillips) $[6, p$. 134]. A vector measure $F: \rightarrow X$ is of the form $F(E)=$ Bochner $-\int_{E} f d \mu, \quad E \in \Sigma$, for some Bochner integrable $F: \Omega \rightarrow X$ if $F$ is $\mu$-continuous, $F$ is of bounded variation and for each $\varepsilon>0$ there exists $E_{\varepsilon} \in \Sigma$ with $\mu\left(\Omega-E_{\varepsilon}\right)<\varepsilon$ such that

$$
\left\{F(E) / \mu(E): E \subset E_{\varepsilon}, \mu(E)>0, E \in \Sigma\right\}
$$

is contained in a weakly compact subset of $X$.

III. Metivier [5]. The converse of Phillips' theorem is true.

IV. (Rieffel) [7]. A vector measure $F: \Sigma \rightarrow X$ is of the form 
$F(E)=$ Bochner $-\int_{E} f d \mu, E \in \Sigma$ for some Bochner integrable $f$ if and only if $F$ is $\mu$-continuous, $F$ is of bounded variation, and for each $\varepsilon>0$ there exists $E_{\varepsilon} \in \Sigma$ with $\mu\left(\Omega-E_{\varepsilon}\right)<\varepsilon$ such that

$$
\left\{F(E) / \mu(E): E \subset E_{\varepsilon}, E \in \Sigma, \mu(E)>0\right\}
$$

is contained in a compact subset of $X$.

Most will agree that of the results listed here the two most powerful are Phillips' theorem and the necessity part of Rieffel's theorem. This is not meant to obscure the fact that the sufficiency part of Rieffel's theorem is proved by elementary means and therein lies its beauty. The next two sections constitute the main part of the paper.

1. Necessary Conditions. Here a simplified version of Rieffel's necessity proof is given. As the proof shows, there is no extra effort needed to carry the proof through in the context of Pettis [4] integrals.

Theorem 1. Let $f: \Omega \rightarrow X$ be strongly measurable and Pettis integrable. If $F(E)=$ Pettis $-\int_{E} f d \mu$ for $E \in \Sigma$, then

(i) $F \ll \mu$

(ii) for each $\varepsilon>0$, there exists $E_{\varepsilon} \in \Sigma$ with $\mu\left(\Omega-E_{\varepsilon}\right)<\varepsilon$ such that

$$
\left\{F(E) / \mu(E): E \subset E_{\varepsilon}, \mu(E)>0, E \in \Sigma\right\}
$$

is contained in a compact subset of $X$.

(iii) If $f$ is also Bochner integrable, then $F$ is of bounded variation.

Proof. (i) and (iii) are standard facts. For (ii), choose a sequence $\left\{f_{n}\right\}$ of measurable simple functions converging almost everywhere to $f$. If $\varepsilon>0$ is given, Egoroff's theorem establishes a set $E_{\varepsilon} \in \Sigma$ with $\mu\left(\Omega-E_{\varepsilon}\right)<\varepsilon$ such that $f_{n}$ converges to $f$ uniformly on $E_{\varepsilon}$. In particular $f$ is bounded on $E_{s}$, since all of the $f_{n}$ 's are bounded on $E_{\varepsilon}$. Hence the Bochner integral $t(g)=\int_{E_{\varepsilon}} g f d \mu$ and $t_{n}(g)=\int_{E_{\varepsilon}} g f_{n} d \mu$ exist for all $g \in L^{1}$ and define bounded linear operators of $L^{1}$ into $X$. Now note that is $g \in L^{1}$ and $\|g\|_{1} \leqq 1$,

$$
\begin{aligned}
\left\|\left(t-t_{n}\right) g\right\|_{X} & =\left\|\int_{E_{\varepsilon}}\left(g f-g f_{n}\right) d \mu\right\| \\
& \leqq \int_{E_{\varepsilon}}|g|\left\|f-f_{n}\right\| d \mu \leqq \sup _{\omega \in E_{\varepsilon}}\left\|f(\omega)-f_{n}(\omega)\right\| .
\end{aligned}
$$


Thus the uniform convergence of $f_{n}$ to $f$ on $E_{\varepsilon}$ guarantees $\lim _{n} t_{n}=t$ in the uniform operator topology. But now note that each $t_{n}$ has a finite dimensional range spanned in $X$ by the finite set of values of $f_{n}$. Hence $t$ is a compact operator. Since $\chi_{E} / \mu(E)$ has norm 1 for each $E \in \Sigma$ of positive $\mu$-measure and $t\left(\chi_{E}\right)=F(E)$ for $E \in \Sigma, E \subset E_{\varepsilon}$, one sees immediately that $\left\{(F(E) / \mu(E)): E \in \Sigma, E \subset E_{\varepsilon}\right\}$ is norm conditionally compact in $X$.

2. Sufficient conditions. The program here is to use Rieffel's necessity condition together with the Dunford-Pettis theorem to show quickly that every weakly compact operator on $L^{1}(\Omega, \Sigma, \mu)$ has a separable range. This will prove that the Dunford Pettis theorem describes the arbitrary weakly compact operator on $L^{1}(\Omega, \Sigma, \mu)$. With this, it is not hard to recover Phillips' result. This line of reasoning has some interest because it shows that Phillips' theorem can be deduced directly, at the discretion of the reader, from the DunfordPettis theorem or from Rieffel's theorem.

As Rieffel emphasizes in his paper, the main hurdle between his theorem and Phillips' theorem is verifying a nontrivial separability condition. This separability condition is equivalent to showing that a weakly compact operator $t: L^{1} \rightarrow X$ has a separable range. In the literature the standard proof of this is to show that such an operator maps weakly compact sets into norm compact sets. The following proof teams Rieffel's theorem with the Dunford-Pettis theorem to obtain

Lemma 2. A weakly compact $t: L^{1}(\Omega, \Sigma, \mu) \rightarrow X$ has a separable range.

Proof. Consider $\left\{\chi_{E}: E \in \Sigma\right\}=S$. The closed linear span of this set in $L^{1}(\Omega, \Sigma, \mu)$ is all of $L^{1}(\Omega, \Sigma, \mu)$. Hence if it can be shown that $t(S)$ is separable, then the linearity and continuity of $t$ will guarantee that $t$ has a separable range. Now to show $t(S)$ is separable, it will be shown that $t(S)$ is conditionally compact in $X$ and separable a fortiori.

For this, let $\left\{\chi_{E_{n}}\right\} \subset S$, and let $\Sigma_{0}$ be the $\sigma$-algebra generated by $\left\{\chi_{E_{n}}\right\}$. Then since $\Sigma_{0}$ is countably generated, $L^{1}\left(\Sigma_{0}\right)=\left\{g \in L^{1}(\Omega, \Sigma, \mu): g\right.$ is measurable with respect to $\left.\Sigma_{0}\right\}$ is also separable. Hence

$$
t: L^{1}\left(\Sigma_{0}\right) \longrightarrow X
$$

is a weakly compact operator whose range is separable. By the Dunford Pettis Theorem I, there exists a strongly $\left(\Sigma_{0}-\right)$ measurable essentially bounded function $f: \Omega \rightarrow X$ such that 


$$
t(g)=\text { Bochner }-\int_{\Omega} g f d \mu, g \in L^{1}\left(\Sigma_{0}\right) .
$$

Now let $\varepsilon>0$ be given. By Rieffel's Theorem IV there exists a set $E_{\varepsilon} \in \Sigma_{0}$ such that $\mu\left(\Omega-E_{\varepsilon}\right)<\varepsilon /($ ess $\sup \|f\|+1)$ and a norm compact set $A_{\varepsilon} \subset X$ such that

$$
\left\{\int_{E} f d \mu / \mu(E): E \in \Sigma_{0}, E \subset E_{\varepsilon}\right\} \subset A_{\varepsilon} .
$$

Next note that the set $A_{\varepsilon}^{\prime}=\left\{\alpha x: 0 \leqq \alpha \leqq \mu(\Omega) ; x \in A_{\varepsilon}\right\}$ is also compact since $A_{\varepsilon}$ is compact. Also note that

$$
t\left(\chi_{E_{n}}\right)=\int_{E_{n}} f d \mu=\int_{E_{n} \cap E_{\varepsilon}} f d \mu+\int_{E_{n}-E_{\varepsilon}} f d \mu .
$$

Now

$$
\int_{E_{n} \cap E_{\varepsilon}} f d \mu \in \mu\left(E_{n} \cap E_{\varepsilon}\right) A_{\varepsilon} \subset A_{\varepsilon}^{\prime}
$$

and

$$
\left\|\int_{E_{n}-E_{\varepsilon}} f d \mu\right\| \leqq \operatorname{ess} \sup \|f\| \mu\left(\Omega-E_{\varepsilon}\right)<\varepsilon .
$$

Hence $t\left(\chi_{E_{n}}\right)$ is within $\varepsilon$ of a member of the compact set $A_{\varepsilon}^{\prime}$. It follows that $\left\{t\left(\chi_{E E n}\right)\right\}$ is totally bounded and therefore norm conditionally compact; i.e., $\left\{t\left(\chi_{E n}\right)\right\}$ has a convergent subsequence. But this proves $t(S)$ is conditionally compact and separable.

Another application of the Dunford-Pettis theorem yields

THEOREM 2. Let $F: \Sigma \rightarrow X$ be a $\mu$-continuous vector measure such that for each $\varepsilon>0$ there exists $E_{\varepsilon} \in \Sigma$, with $\mu\left(\Omega-E_{\varepsilon}\right)<\varepsilon$ such that

$$
B_{\varepsilon}=\left\{F(E) / \mu(E): E \subset E_{\varepsilon}, E \in \Sigma \mu(E)>0\right\}
$$

is contained in a weakly compact subset of $X$. Then there exists a strongly measurable Pettis integrable function $f: \Omega \rightarrow X$ such that for $E \in \Sigma$

$$
F(E)=\text { Pettis }-\int_{E} f d \mu .
$$

If, in addition, $F$ is of bounded variation, then $f$ is Bochner integrable and for $E \in \Sigma$,

$$
F(E)=\text { Bochner }-\int_{E} f d \mu
$$


Proof. For each $\varepsilon=1 / n, n$ a positive integer, choose $E_{\varepsilon}$ as above. Define $t$ on the simple functions of the form $\sum_{i=1}^{n} \alpha_{i} \chi_{E_{i}} \alpha_{i}$ real, $\left\{E_{i}\right\} \subset \Sigma$, disjoint by

$$
t\left(\sum_{i=1}^{n} \alpha_{i} \chi_{E_{i}}\right)=\sum_{i=1}^{n} \alpha_{i} F\left(E_{i} \cap E_{\varepsilon}\right)=\sum_{i=1}^{n} \alpha_{i} \mu\left(E_{i} \cap E\right) \frac{F\left(E_{i} \cap E_{\varepsilon}\right)}{\mu\left(E_{i} \cap E_{\varepsilon}\right)} .
$$

Usual arguments show $t$ is linear. Moreover, if $\sum_{i=1}^{n}\left|\alpha_{i}\right| \mu\left(E_{i}\right) \leqq 1$, then the above computation shows $t\left(\sum_{i=1}^{n} \alpha_{i} \mu\left(E_{i}\right)\right) \subset$ closed convex hull of $\left(B_{\varepsilon}-B_{\varepsilon}\right)^{1}$ which is weakly compact by the Krein-Smulian theorem [2, p. 434]. Hence $t$ maps a dense subset of the unit ball of $L^{\prime}(\Omega, \Sigma, \mu)$ into a weakly compact set and thus has a weakly compact extension to all of $L^{1}(\Omega, \Sigma, \mu)$. By the above lemma, $t$ has a separable range and by the Dunford-Pettis theorem there exists a strongly measurable $f_{\varepsilon}$ vanishing off $E_{\varepsilon}$ such that

$$
t(g)=\text { Bochner }-\int_{E_{\varepsilon}} g f_{\varepsilon} d \mu
$$

for all $g \in L^{1}(\Omega, \Sigma, \mu)$. Now if this is done for each $\varepsilon=1 / n$, one can produce an increasing sequence of measurable sets $\left\{E_{n}\right\}$ such that $\mu\left(\Omega-E_{n}\right) \rightarrow 0$ and a sequence of strongly measurable Bochner integrable functions $\left\{f_{n}\right\}$ such that $F\left(E \cap E_{n}\right)$ is given by the Bochner integral $\int_{E \cap E_{n}} f_{n} d \mu$ for $E \in \Sigma$. Clearly $f_{n} \chi_{E_{m}}=f_{m}$ a.e., for $n \geqq m$ since $E_{n} \uparrow$. ${ }^{E E_{n}}$ Also since $E_{n} \uparrow \Omega$, it is evident that there exists a strongly measurable function $f$ such that $f_{n} \chi_{E_{n}}=f \chi_{E_{n}}$ a.e., Now note that if $E \in \Sigma$ is arbitrary, the $\mu$-continuity of $F$ and the fact that $\lim _{n} \mu\left(\Omega-E_{n}\right)=0$ imply

$$
F(E)=\lim _{n} F\left(E \cap E_{n}\right)=\lim _{n} \int_{E \cap E_{n}} f_{n} d \mu=\lim _{n} \int_{E \cap E_{n}} f d \mu
$$

strongly in $X$. Thus $x^{*} F(E)=\lim _{n} \int_{E \cap E_{n}} x^{*} f d \mu$ for all $x^{*} \in X^{*}$, the dual space of $X$. Next note that for $x^{*} \in X^{*}, x^{*} F$ is a bounded signed measure on $\Sigma$. Hence it is of finite variation $\left|x^{*} F\right|$, and

$$
\int_{\Omega}\left|x^{*} f\right| d \mu=\lim _{n} \int_{E_{n}}\left|x^{*} f\right| d \mu=\lim _{n}\left|x^{*} F\right|\left(E_{n}\right)=\left|x^{*} F\right|(\Omega)<\infty .
$$

Therefore $x^{*} f \in L^{1}(\Omega, \Sigma, \mu)$ and by the dominated convergence theorem,

$$
x^{*} F(E)=\lim _{n} \int_{E \cap E_{n}} x^{*} f d \mu=\int_{E} x^{*} f d \mu .
$$

This shows that $F$ is the indefinite Pettis integral of $f$.

${ }^{1}$ An obvious modification holds if $X$ is a complex $B$-space. 
To prove (b), suppose in addition that $F$ is of bounded variation. Replacing $\left|x^{*} f\right|$ by $\|f\|$ and $\left|x^{*} F\right|$ by $|F|$, the variation of $F$, in the above paragraph shows that $\|f\| \in L^{1}(\mu)$, and hence that $f$ is Bochner integrable; i.e., $F(E)=\int_{E} f d \mu$ for all $E \in \Sigma$.

4. Concluding remarks. Here some observations and theorems are given without full proofs.

Fact 1. If $f: \Omega \rightarrow X$ is strongly measurable and Pettis integrable then Pettis - $\int_{E} f d \mu$ can be realized as an "improper" Bochner integral $=$ strong $\lim _{n}$ Bochner $-\int_{E_{\cap} E_{n}}$ fd f for some sequence $\left\{E_{n}\right\} \subset \Sigma$ such that $E_{n} \uparrow \Omega$.

Fact 2. If $X$ is reflexive and $F: \Sigma \rightarrow X$ is a vector measure whose variation is $\sigma$-finite, then $F$ has a separable range.

Fact 3. If $X$ is reflexive and $F: \Sigma \rightarrow X$ is $\mu$-continuous, then $F$ is representable as a $\mu$-Pettis integral if and only if its variation is $\sigma$-finite and as a $\mu$-Bochner integral if and only if its variation is finite.

Finally it is noted that Rieffel's interesting Radon-Nikodým theorem [8] dealing with dentable subsets of Banach spaces does not seem to fit conveniently into the treatment of this paper. It would be interesting to see how this theorem relates to the others.

\section{REFERENCES}

1. N. Dunford and B. J. Pettis, Linear operations on summable functions, Trans. Amer. Math. Soc., 47 (1940), 323-392.

2. N. Dunford and J. T. Schwartz, Linear Operators, Part I., Interscience, New York, 1958.

3. R. E. Edwards, Functional Analysis, Holt, Rhineheart, Winston, New York, 1965.

4. E. Hille and R. S. Phillips, Functional Analysis and Semigroups, Amer. Math. Soc. Solloq. Pub. Vol. 31, New York, 1957.

5. M. Metivier, Martingales a valeurs vectorielles. Application a la derivation des mesures vectorielles, Ann. Inst. Fourier Grenoble 2 (1967), 175-208.

6. R. S. Phillips, On weakly compact subsets of a Banach space, Amer. J. Math., 65 (1943), 108-136

7. M. A. Rieffel, The Radon-Nikodym theorem for the Bochner integral, Trans. Amer. Math. Soc., 131 (1968), 466-487.

8. - Dentable Subsets of Banach Spaces with Applications to a Radon-Nikodym Theorem, in Functional Analysis by B. R. Gelbaum, Editor, Thompson Book Co., Washington, 1967.

Received January 28, 1971. The second author was supported in part by NSF Grant GP-14592. 


\section{PACIFIC JOURNAL OF MATHEMATICS}

\section{EDITORS}

\author{
H. SAMELSON \\ Stanford University \\ Stanford, California 94305 \\ C. R. HовBY \\ University of Washington \\ Seattle, Washington 98105
}

J. DUGUndis

Department of Mathematics

University of Southern California

Los Angeles, California 90007

RICHARD ARENS

University of California

Los Angeles, California 90024

\section{ASSOCIATE EDITORS}
E. F. BeCKenbaCH
B. H. NeUmanN
F. WOLF
K. YoshidA

\section{SUPPORTING INSTITUTIONS}

\author{
UNIVERSITY OF BRITISH COLUMBIA \\ CALIFORNIA INSTITUTE OF TECHNOLOGY \\ UNIVERSITY OF CALIFORNIA \\ MONTANA STATE UNIVERSITY \\ UNIVERSITY OF NEVADA \\ NEW MEXICO STATE UNIVERSITY \\ OREGON STATE UNIVERSITY \\ UNIVERSITY OF OREGON \\ OSAKA UNIVERSITY \\ UNIVERSITY OF SOUTHERN CALIFORNIA
}

\author{
STANFORD UNIVERSITY \\ UNIVERSITY OF TOKYO \\ UNIVERSITY OF UTAH \\ WASHINGTON STATE UNIVERSITY \\ UNIVERSITY OF WASHINGTON

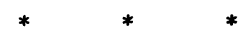 \\ AMERICAN MATHEMATICAL SOCIETY \\ CHEVRON RESEARCH CORPORATION \\ NAVAL WEAPONS CENTER
}

The Supporting Institutions listed above contribute to the cost of publication of this Journal, but they are not owners or publishers and have no responsibility for its content or policies.

Mathematical papers intended for publication in the Pacific Journal of Mathematics should be in typed form or offset-reproduced, (not dittoed), double spaced with large margins. Underline Greek letters in red, German in green, and script in blue. The first paragraph or two must be capable of being used separately as a synopsis of the entire paper. The editorial "we" must not be used in the synopsis, and items of the bibliography should not be cited there unless absolutely necessary, in which case they must be identified by author and Journal, rather than by item number. Manuscripts, in duplicate if possible, may be sent to any one of the four editors. Please classify according to the scheme of Math. Rev. Index to Vol. 39. All other communications to the editors should be addressed to the managing editor, Richard Arens, University of California, Los Angeles, California, 90024.

50 reprints are provided free for each article; additional copies may be obtained at cost in multiples of 50 .

The Pacific Journal of Mathematics is published monthly. Effective with Volume 16 the price per volume (3 numbers) is $\$ 8.00$; single issues, $\$ 3.00$. Special price for current issues to individual faculty members of supporting institutions and to individual members of the American Mathematical Society: $\$ 4.00$ per volume; single issues $\$ 1.50$. Back numbers are available.

Subscriptions, orders for back numbers, and changes of address should be sent to Pacific Journal of Mathematics, 103 Highland Boulevard, Berkeley, California, 94708.

PUBLISHED BY PACIFIC JOURNAL OF MATHEMATICS, A NON-PROFIT CORPORATION

Printed at Kokusai Bunken Insatsusha (International Academic Printing Co., Ltd.), 7-17, Fujimi 2-chome, Chiyoda-ku, Tokyo, Japan. 


\section{Pacific Journal of Mathematics}

Vol. 38, No. $2 \quad$ April, 1971

Richard Davis Anderson and Thomas Ashland Chapman, Extending

homeomorphisms to Hilbert cube manifolds .................. 281

Nguyen Huu Anh, Restriction of the principal series of $\operatorname{SL}(n, \mathbf{C})$ to some

reductive subgroups................................ 295

David W. Boyd, Indices for the Orlicz spaces . . . . . . . . . . . . 315

William Garfield Bridges, The polynomial of a non-regular digraph ...... 325

Billie Chandler Carlson, Robert K. Meany and Stuart Alan Nelson, Mixed

arithmetic and geometric means........................ 343

H. A. Çelik, Commutative associative rings and anti-flexible rings ...... 351

Hsin Chu, On the structure of almost periodic transformation groups ...... 359

David Allyn Drake, The translation groups of n-uniform translation

Hjelmslev planes ................................ 365

Michael Benton Freeman, The polynomial hull of a thin two-manifold . . . . 377

Anthony Alfred Gioia and Donald Goldsmith, Convolutions of arithmetic

functions over cohesive basic sequences .................... 391

Leslie C. Glaser, A proof of the most general polyhedral Schoenflies

conjecture possible ................................

Thomas Lee Hayden and Ted Joe Suffridge, Biholomorphic maps in Hilbert

space have a fixed point ................................ 419

Roger Alan Horn, Schlicht mappings and infinitely divisible kernels ...... 423

Norman Ray Howes, On completeness ...................... 431

Hideo Imai, Sario potentials on Riemannian spaces................ 441

A. A. Iskander, Subalgebra systems of powers of partial universal

algebras.

Barry E. Johnson, Norms of derivations of $\mathscr{L}(\mathrm{X})$.

David Clifford Kay and Eugene W. Womble, Axiomatic convexity theory and relationships between the Carathéodory, Helly, and Radon numbers

Constantine G. Lascarides, A study of certain sequence spaces of Maddox

and a generalization of a theorem of Iyer .............

C. N. Linden, On Blaschke products of restricted growth .

John S. Lowndes, Some triple integral equations ................. 515

Declan McCartan, Bicontinuous preordered topological spaces ......... 523

S. Moedomo and J. Jerry Uhl, Jr., Radon-Nikodým theorems for the Bochner and Pettis integrals ...

Calvin Cooper Moore and Joseph Albert Wolf, Totally real representations

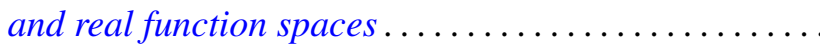

Reese Trego Prosser, A form of the moment problem for Lie groups. ... 